\title{
EVALUATION OF THE CUTTING FORCE ON VINE BRANCHES IN WINTER PRUNING
}

\author{
Fabio Pezzi, Giorgio Ade, Francesco Bordini, Alessandro Giunchi
}

\section{Introduction}

After thirty years of studies, aimed to the improvement of techniques, machines and equipment [Aldini 2004, Gubiani 1994, Poni 1998, Pezzi 2006], the practice of mechanical pruning is now in great expansion due to the increase of costs of labour, to the decreasing supply of skilled labour [Martinez 2003], to the strong public impulse for renewing the vineyards [Regione 2001].

There are three main systems of winter pruning: manual, mechanical and mechanical finished by manual labour. Mechanical pruning is faster (91 to $95 \%$ less) and cheaper than the manual one, but increases the number of old and badly positioned spurs. Mechanical pruning followed by manual labour gives an intermediate result. The effects on the quality of grape are related to the kind of pruning, the quality of hand finishing and also to the variety. [Pezzi 2006, Arrivo 2001].

Under European conditions, mechanical pruning is generally integrated with manual finishing.

The diffusion of mechanical pruning may arise some doubts about the quality of cut because it sometimes appears not to be the best solution as to precision and cleanliness. This aspect, probably influenced by the model and the application of pruning machines, might also be affected by the characteristics of the vine canes, in particular by their resistance to the cutting.

This work reports the results of laboratory measurements of the cutting force of vine branches during winter pruning on different vine-type and of field trials on the quality level of mechanical pruning in different vineyards.

Paper received 17.03.2008; accepted 03.03.2009

Prof. FABIO PEZZI (fabio.pezzi@unibo.it) associate professor, prof. Giorgio Ade associate professor, dr. Francesco Bordini PhD, dr. AlESSANDRo GiUNCHI PhD, Economics and Engineering Department, University of Bologna, V.le Fanin, 50 - 40127 Bologna, Italy.

\section{Materials and methods}

The evaluation of the cutting force of vine branches during winter pruning has considered three different parameters:

- variety of vine,

- branch size,

- pruning period.

Three vine varieties were used: Trebbiano Romagnolo, Sangiovese and Cabernet Sauvignon, trained to the GDC (Geneva Double Curtain) system in the fields of the Experimental Station of Tebano, Faenza. The samples of branches were collected during three different periods: early pruning (nov/14/2004), middle pruning (jan/13/2005) and late pruning (mar/15/ 2005). The collected samples were divided according to three classes of diameter: 3 to 5,5 to 7 and 7 to $9 \mathrm{~mm}$.

The cutting force of the branches has been evaluated in term of penetration force of a triangular-section blade, $3 \mathrm{~mm}$ thick, moved down with a constant speed of $0,1 \mathrm{~mm} / \mathrm{s}$. The maximum force measured corresponded to the rupture force during the experimental process.

ASAE standard [ASAE 1989] for determining mechanical attributes of food texture, resistance to mechanical injury, and force-deformation behaviour of convex shaped food materials, defines rupture point as the point on the force-deformation curve at which the sample shows a visible or invisible failure in the form of breaks or cracks. This point is detected by a continuous decrease of the force in the force- deformation diagram.

The experiment was conduced using a texture analyzer TA-HDi (Stable Micro System UK) equipped with a load cell of $2.5 \mathrm{kN}$ maximum load and $1 \mathrm{~N}$ sensitivity (Fig. 1). The data were acquired by a software integrated with the instrumentation at 200 points per second resolution. Each experiment was carried out on 50 samples.

In the intermediate period (january 2005) field trials were carried out to verify the quality level of mechanical pruning in different varieties of vine, in order to define the spur damages. The pruning was with spurs $15-20 \mathrm{~cm}$ long. 


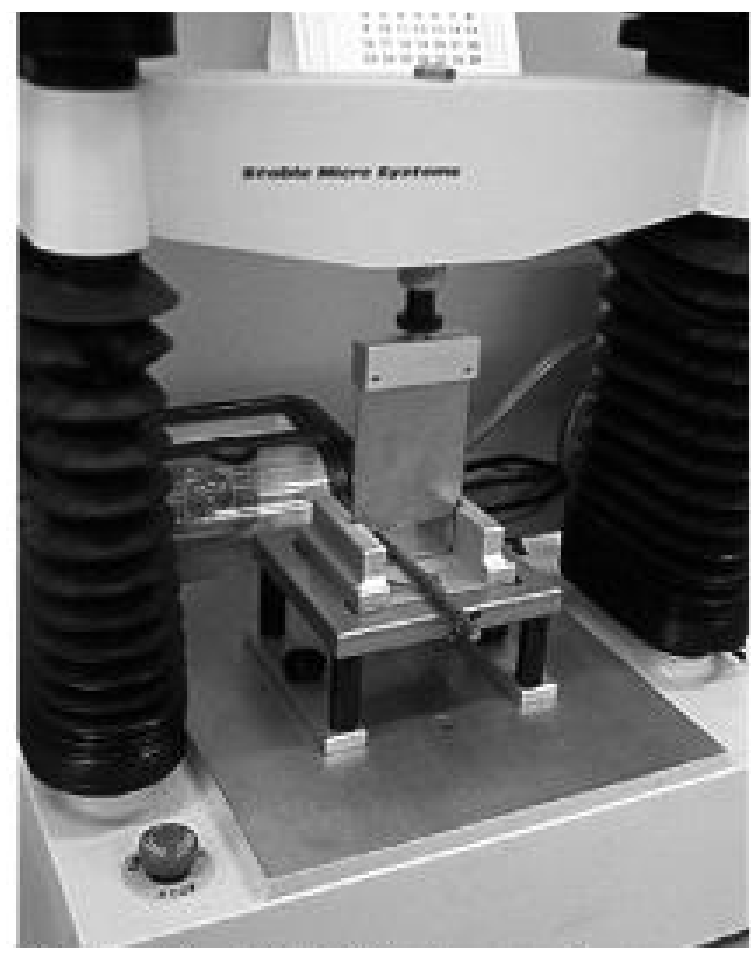

Fig. 1 - The TA-HDi texture analyzer.

The damages have been classified visually as: light (irregular cuts with longitudinal cracks) and severe (partial or total brackages of the spurs or ripping-off of the canes). Normally, the first ones have no influence on the yield, while the second ones seriously affect the regular vegetation growing and the production.

In each thesis the spurs present on a base of 6 meters of row have been counted. Every count has been repeated on 4 bases. The mean spur density was about 15 spurs/meter.

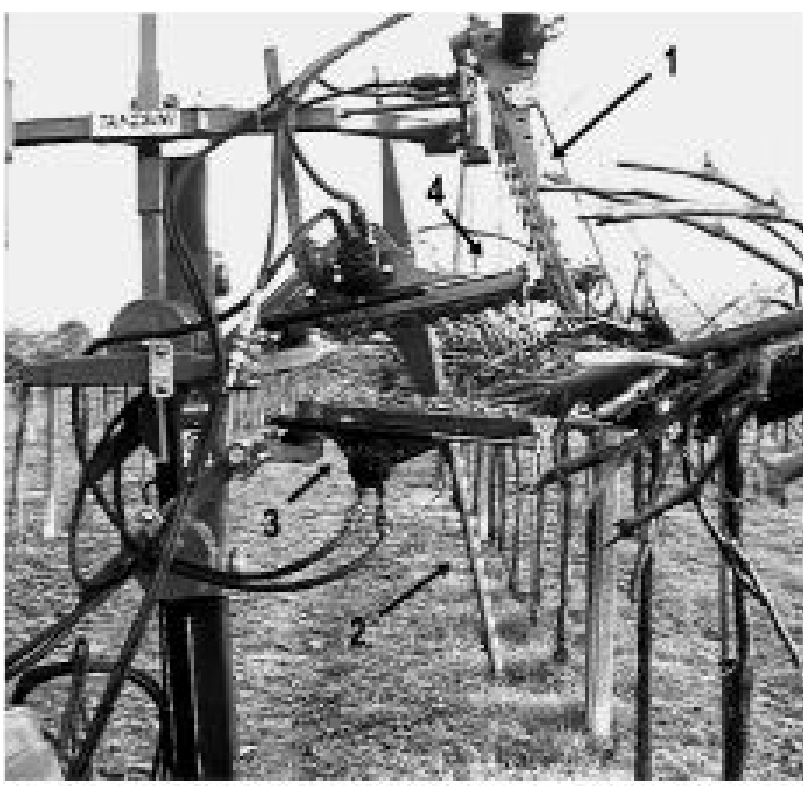

Fig. 2 - Blades operation of the pruning machine. 1: internal cut (floating); 2: external - vertical cut; 3 and 4: lower and upper horizontal cut.
The operations were performed by a multiple oscillating cutter bar (mod. Trimmer, Tanesini Technology) fitted frontally to the tractor (Fig. 2). The machine was equipped with four blades, whose position and function are illustrated in figure 2 . The blades were driven by hydraulic motors. The travel speed was 2.8 $\mathrm{km} / \mathrm{h}$ and the blades oscillation frequency varied from 4,3 to $6,2 \mathrm{~Hz}$, which is a normally used condition for this type of pruning equipment.

\section{Results}

Cutting resistance showed similar trends, but significant differences in the maximum force between the three different vine stocks. The curves started with a fast increase of the cutting force, which reached the maximum at the rupture point; the following peaks were due to the uncut fibres dragging (Fig. 3).

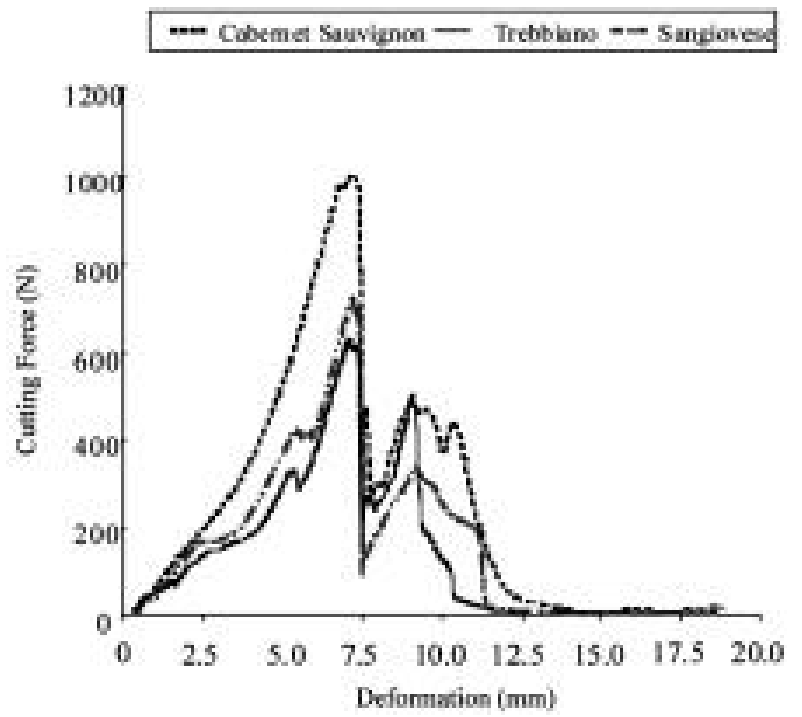

Fig. 3 - Examples of force-deformation curves obtained with the three vine types.

\section{Vine comparison}

Taking into account the medium diameter class (5 to $7 \mathrm{~mm}$ ), which has been more frequently found during vineyard sampling, the statistical analysis showed a fairly good homogeneity of the groups and significant difference between the vines (Table 1). Com-

\begin{tabular}{lcl}
\hline \multicolumn{1}{c}{ Vine } & Force max. (N) Standand erroe (\%) \\
\hline Trebbiano Romagnolo & $675.3 \mathrm{a}$ & 24.7 \\
Sangiovese & $813.5 \mathrm{~b}$ & 25.2 \\
Cabernet Sauvignon & $1175.1 \mathrm{c}$ & 24.7 \\
\hline
\end{tabular}

TABLE 1 - Mean values of maximum cutting force measured for the 3 vine varieties ( 5 to $7 \mathrm{~mm}$ class) Different letters indicate significant difference for $\mathrm{P} \leq 0.05$. 

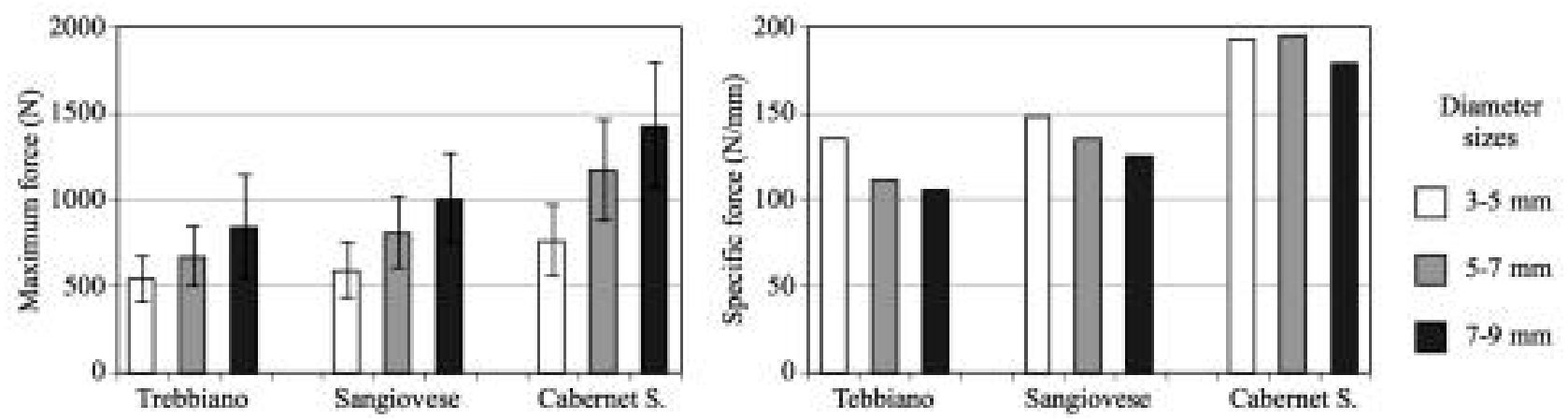

Fig. 4 - Cutting force measured for the different diameter of the 3 vine types. On the left are shown the values of maximum force, on the right the rate between the force and the diameter.

\begin{tabular}{ccccc}
\hline Vine & Pruning date & $\begin{array}{c}\text { Moisture } \\
(\%)\end{array}$ & $\begin{array}{c}\text { Max force } \\
(\mathrm{N})\end{array}$ & $\begin{array}{c}\text { Standard Error } \\
(\%)\end{array}$ \\
\hline Trebbiano & $14 \mathrm{nov}$ & 50.0 & 627.2 & 28.3 \\
& $13 \mathrm{jan}$ & 50.6 & 675.3 & 22.1 \\
& $15 \mathrm{mar}$ & 54.9 & 497.1 & 28.8 \\
\cline { 2 - 5 } Sangiovese & $14 \mathrm{nov}$ & 50.2 & 654.7 & 28.8 \\
& $13 \mathrm{jan}$ & 49.2 & 813.5 & 22.5 \\
& $15 \mathrm{mar}$ & 53.5 & 595.4 & 28.8 \\
\hline \multirow{2}{*}{ Cabernet S. } & $14 \mathrm{nov}$ & 47.3 & 795.8 & 28.8 \\
& $13 \mathrm{jan}$ & 45.3 & 1175.1 & 22.1 \\
& $15 \mathrm{mar}$ & 48.9 & 801.1 & 28.8 \\
\hline
\end{tabular}

TABLE 2 - Moisture and relative cutting force measured on the second class of diameter at different times, during winter.

pared with Cabernet S. which required the highest cutting force, the other varieties showed values by $31 \%$ (Sangiovese) and 43\% (Trebbiano) lower.

\section{Comparison between classes of diameter}

The comparison between the three classes of diameter showed, in all cases, significant differences (Fig. 4). The cutting force increased with the increase of diameter and the increment ranged from $56 \%$ to $86 \%$. Rating the values of the maximum force to the corresponding diameter (specific force), the differences between the vine varietes decreased, and for the largest diameters lower values were measured.

\section{Pruning date}

During the winter season the vines showed a variation in cutting force related to the water content of the branches (Table 2). The highest values of cutting force were found in the second period of sampling, corresponding to the complete vegetative rest, whereas the lowest values were measured in the third period of sampling, when the tissues of the branches were more turgid.

Respect to the second period, when the cutting force reached its maximum, in the latest period it was possible to reduce it by $26 \%$ in Trebbiano e Sangiovese and by $32 \%$ in Cabernet Sauvignon.

\section{Mechanical pruning efficiency}

The qualitative evaluation of mechanical pruning carried out in the second half of January, showed a fairly good frequency of light damages (irregularity or breakage of cutting surfaces) and a small percentage of severe damages (partially or totally ripped-off branches) (Fig. 5).

The effect of damages appeared to be related to the cutting force of the three vines. The highest damages were found for Cabernet. Is interesting to observe that the correct set up of the pruning machine is basic to reduce or eliminate the damages to the vegetation.

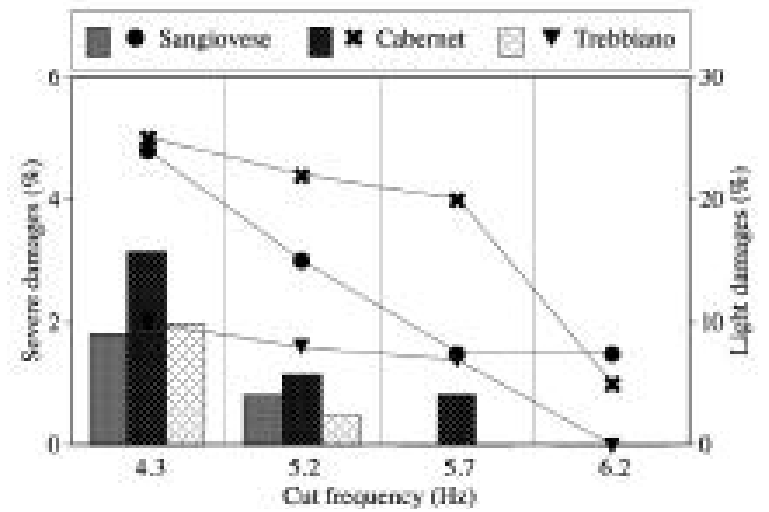

Fig. 5 - Severe damages (histogram) and light damages (dots) on the three vines, related to the oscillation frequency of the mower blade. 


\section{Conclusions}

The experiment shows how the cutting force of vine canes during vegetative rest is a parameter which depends on vine variety, branch thickness and pruning period. The variability of these parameters, which can be considerable, affects directly the pruning results. High values of cutting force can generate tiredness of operator in manual pruning or cutting damages during mechanical pruning.

A percentage of damages higher than $2-3 \%$ is certainly to be avoided for the sanitary problems that they can cause to the permanent cordon.

Also an incidence of $20-25 \%$ of light damages is to be considered negative, not only in the infrequent case of totally mechanical pruning, but also because it slows down the hand finishing which usually follows the mechanical operation.

The results can lead to an improvement of the optimization of the pruning times scheduling and to an increase of mechanical efficiency according to the vine type. When the mechanical pruning is necessarily to be made during the vegetation rest, when the wood is harder, it is better using a higher oscillation frequency of the blades. A high frequency is always advisable for vines like Cabernet, which have a high cutting resistance.

\section{References}

Aldini E., InTRIERI C., Viticoltura meccanizzata (Mechanized viticulture), 2004, Edagricole, Bologna.

Arrivo A., Bellomo F., D’ ANTONIo P., Limiti di convenienza per l'impiego delle macchine operatrici. Applicazione a macchine mono e polifunzionali per la viticoltura (Convenience limits of implement employment. Application to mono and multifuncion implements for grape growing). Rivista di Ingegneria Agraria, 2001, 32(3), 147-157.

ASAE S368.1. Compression test of food material of convex shape. ASAE Standards, 1989, 368-371.

Gubiani R., Pergher G., Gasparinetti P., La potatura meccanica della vite nell'ambito della meccanizzazione integrale (Vineyard mechanical pruning in full mechanization). L'Informatore Agrario, 1994, 44, 27-34.

Martinez de Toda F., TARdaguila J., Forme d'allevamento della vite e modalità di distribuzione dei fitofarmaci (Vine- yard growing shapes and pesticides distribution methods). Bayer CropScience S.r.l., 2003, Milano.

PeZZI F., Bordini F., La potatura meccanica nel vigneto: aspetti tecnici, qualitativi ed economici di differenti livelli di meccanizzazione (Vineyard mechanical winter pruning: technical, qualitative and economical aspects of different mechanization levels). Rivista di Ingegneria Agraria, 2006, 37(1), 55-63.

Poni S., Bellanti G., La potatura meccanica dei vigneti (Mechanical pruning of vineyards). Vignevini,1988, 10.

Regione Emilia Romagna, Piano Regionale Ricostruzione e Ristrutturazione Vigneti (Regional plan for vineyards rebuilding and renovation) (Applicazione del REG. CE, 1493/1999) - Del. 186 del 30-5-2001.

\section{SUMMARY}

Mechanical pruning, usually integrated with manual finishing, still excites some doubts regarding the quality of the cut which appears not to be the best as precision and cleanliness. This aspect, probably conditioned by the model and the application of pruning machines, might also be affected by the characteristics of the vine branches in particular by their cutting force.

In order to evaluate the cutting force on different vine type, laboratory and field trails were carried out. The experiments were set in order to evaluate this parameter during winter pruning in relation to three variables: vine type; branch size; pruning time.

The results show how the cutting resistance of vine branches during vegetative rest depends on vine variety (Trebbiano $675 \mathrm{~N}$ Cabernet $1175 \mathrm{~N}$ ), on the diameter of the canes (increase of force from $56 \%$ to $86 \%$ between the classes of diameter) and on the pruning date $(26 \%$ decrease of the cutting force in the latest period for Trebbiano and Sangiovese, and $32 \%$ for Cabernet Sauvignon).

Such variations, which can be considerable, affect directly the pruning results. High values of cutting force can generate tiring of operator in manual pruning or cutting damages on the vegetation during mechanical pruning.

Keywords: mechanical pruning, vine grape, cutting force. 